\title{
A Novel Risk Scoring Tool to Predict Saphenous Vein Graft Occlusion in Patients with Type 2 Diabetes Mellitus After Cardiac Artery Bypass Graft Surgery
}

\section{Yujing Cheng}

Capital Medical University Affiliated Anzhen Hospital

\section{Xiaoteng Ma}

Capital Medical University Affiliated Anzhen Hospital

\section{Xiaoli Liu}

Capital Medical University Affiliated Anzhen Hospital

\section{Yingxin Zhao}

Capital Medical University Affiliated Anzhen Hospital

\section{Yan Sun}

Capital Medical University Affiliated Anzhen Hospital

\section{Dai Zhang}

Capital Medical University Affiliated Anzhen Hospital

\section{Qi Zhao}

Capital Medical University Affiliated Anzhen Hospital

\section{Yingkai Xu}

Capital Medical University Affiliated Anzhen Hospital

\section{Yujie Zhou ( $\square$ azzyj12@163.com )}

Capital Medical University Affiliated Anzhen Hospital https://orcid.org/0000-0002-9545-1984

\section{Original investigation}

Keywords: coronary artery bypass grafting, coronary artery disease, graft occlusion, type 2 diabetes mellitus

Posted Date: August 4th, 2020

DOl: https://doi.org/10.21203/rs.3.rs-44228/v1

License: (9) This work is licensed under a Creative Commons Attribution 4.0 International License. Read Full License 


\section{Abstract}

Background: Coronary artery bypass grafting (CABG) success is reduced by graft occlusion. Patients with type 2 diabetes mellitus(T2DM) are more likely to develop graft occlusion. Understanding factors associated with graft occlusion may improve T2DM patient outcomes. The aim of this study was to develop a predictive risk score for saphenous vein graft (SVG) occlusion in T2DM patients after CABG.

Methods: This retrospective cohort study enrolled 3716 CABG patients with T2DM from January 2012 to March 2013. The development cohort included 2477 patients and the validation cohort included 1239 patients. The baseline clinical data at index CABG was analyzed for their independent impact on graft occlusion in our study using Cox proportional hazards regression. The predictive risk scoring tool was weighted by beta coefficients from the final model. Concordance (c)-statistics and comparison of the predicted and observed probabilities of predicted risk were used for discrimination and calibration.

Results: A total of 959 (25.8\%) out of 3716 patients developed at least one SVG occlusion. Significant risk factors for occlusion were male sex, estimated glomerular filtration rate $<90$, smoking (currently), hyperuricemia, dyslipidemia, prior percutaneous coronary intervention (PCl), a rising number of lesion vessels, and SVG. On-pump surgery, and the use of angiotensin-converting enzyme inhibitors (ACEI)/angiotensin receptor blockers (ARB) and calcium channel blockers (CCB) were protective factors. The risk scoring tool with 11 variables was developed from the derivation cohort, which delineated each patient into risk quartiles. The c-statistic for this model was 0.71 in the validation cohort.

Conclusions: An easy-to-use risk scoring tool that used common clinical variables was developed and validated. The scoring tool accurately estimated the risk of late SVG occlusion in T2DM patients after CABG.

\section{Background}

Coronary artery disease (CAD) is the leading cause of mortality in people with type 2 diabetes mellitus $(T 2 D M)(1)$.Coronary artery bypass grafting $(C A B G)$ surgery is a widely used treatment for complex CAD that improves patient outcomes and prognosis, which was associated with significantly lower long-term adverse clinical outcomes compared to $\mathrm{PCl}$ in patients with $\mathrm{T} 2 \mathrm{DM}(2,3)$. However, some patients experience myocardial ischemia recurrence after CABG. A complex interaction is emerging between platelet function, antiplatelet drugs, coronary diseases and ischemia/reperfusion injury, especially in diabetic conditions(4). Studies have shown that the myocardial ischemic recurrence at 1 and 10 years after CABG are $17 \%$ and $63 \%$, respectively $(5,6)$. The main cause of myocardial ischemic recurrence is graft failure (7). Saphenous vein is the most widely used vascular conduit for CABG (8); however, the estimated rate of occlusion is as high as $42 \%$ at a mean follow-up of 7.5 years (9). Graft occlusion is associated with worse quality of life and reduced long-term survival. T2DM is one of the most important risk factors for graft occlusion. Although the patency of saphenous vein graft (SVG) has been assessed in several studies (10), the specific risk factors for late SVG occlusion in patients with T2DM remain 
unclear. Previous studies have suggested that sex (11), chronic kidney disease(12,13), and off-pump surgery (14) affect graft patency. However, there is no precise scoring model for late SVG occlusion in patients with T2DM.

The risk prediction model is an important tool for risk assessment. The risk scoring system is used to provide risk stratification, identify high-risk patients, control risk factors, and inform strategies to reduce mortality and improve quality of medical care. The previous Saphenous Vein Graft Failure-An Outcomes Study in Coronary Artery Bypass Grafting (SAFINOUS-CABG) score is a simplified 12-variable risk scoring system that performs well in prediction of early SVG occlusion risk. However, the mechanisms of early and late occlusion are different. Late occlusion is due to development of atherosclerosis, which affects long-term clinical outcomes; the treatment is more difficult compared to early occlusion, and the risk factors are diverse. There is no standardized risk scoring system for late SVG occlusion. Therefore, it is of great clinical significance to establish a predictive risk scoring tool that accounts for specificity and accuracy. This study aimed to establish a risk scoring system that is suitable for CABG patients and evaluates the risk of late SVG occlusion.

\section{Methods}

\subsection{Patients}

Using the electronic medical system of Beijing Anzhen Hospital, we retrospectively identified 4021 patients with T2DM who underwent CABG surgery at our cardiac center between January 2012 and March 2013. Subsequently, we followed up with these patients between January 2017 and December 2017 to review and record their postoperative invasive angiography or coronary computed tomography angiography (CTA) results. Patients were excluded unless their medical records contained the following: (1) detailed preoperative angiographic results; (2) saphenous vein used for the graft; (3) results of postoperative invasive angiography or CTA; and (4) detailed information on patency and occlusion of SVG. A total of 3716 patients met the above criteria and were included in the final analysis (Fig. 1).2568 patients were symptomatic, 592 patients underwent invasive angiography or CTA because of acute coronary syndrome. 2526 patients underwent CTA, 1190 patients underwent invasive angiography. All data were retrieved from the electronic medical records system. Patient anonymity was ensured and this study was approved by the Institutional Review Board.

\subsection{Endpoints}

If a patient had at least one SVG occlusion on follow-up invasive angiography or CTA, we regarded the patient to have reached the primary endpoint. The invasive angiography or CTA result was reviewed by two or more experienced cardiologists and a radiologist independently.

\subsection{Rationale for risk factor selection}

Risk factors selection was based on previous studies $(10,11,15-18)$ and clinical experience. Factors chosen were those easily measured and recorded. We recorded data on 38 relevant factors in this study 
(Table 1), and, after primary screening and Cox proportional hazards model analysis, 11 independent risk factors associated with late occlusion were selected. 
Table 1

Patient characteristics

\begin{tabular}{|c|c|c|c|}
\hline & $\begin{array}{l}\text { Derivation cohort } \\
N=2477\end{array}$ & $\begin{array}{l}\text { Validation cohort } \\
N=1239\end{array}$ & P value \\
\hline Age (years) & $59.73 \pm 8.66$ & $59.61 \pm 8.88$ & 0.68 \\
\hline Male gender, n (\%) & $1901(76.7)$ & $918(74.1)$ & 0.08 \\
\hline Obesity, n (\%) & $536(22.3)$ & $243(20.3)$ & 0.17 \\
\hline Hypertension, n (\%) & $1476(59.6)$ & $778(62.8)$ & 0.07 \\
\hline Hyperuricemia, n (\%) & $453(18.3)$ & $225(18.2)$ & 0.96 \\
\hline Dyslipidemia, n (\%) & $1429(57.7)$ & $708(57.1)$ & 0.75 \\
\hline Total cholesterol (mmol/L) & $4.26 \pm 1.20$ & $4.27+1.24$ & 0.81 \\
\hline High-density lipoprotein (mmol/L) & $0.99 \pm 0.24$ & $0.98 \pm 0.22$ & 0.24 \\
\hline Low-density lipoprotein (mmol/L) & $2.60 \pm 0.96$ & $2.62 \pm 1.00$ & 0.46 \\
\hline Triglyceride (mmol/L) & $1.94 \pm 1.48$ & $1.90 \pm 1.30$ & 0.11 \\
\hline Platelet count $(109 / \mathrm{L})$ & $202.87 \pm 58.07$ & $206.78 \pm 60.24$ & 0.30 \\
\hline eGFR< $<0, \mathrm{n}(\%)$ & $1126(45.5)$ & $594(47.9)$ & 0.15 \\
\hline$E F<50, n(\%)$ & 203(9.2) & $125(11.4)$ & 0.06 \\
\hline ACS, n (\%) & $1059(47.4)$ & $562(50.3)$ & 0.12 \\
\hline Smoking, n (\%) & $1073(43.3)$ & $508(41.0)$ & 0.18 \\
\hline Drinking, n (\%) & $290(11.7)$ & $152(12.3)$ & 0.64 \\
\hline Prior stroke, n (\%) & 155(6.3) & $86(6.9)$ & 0.44 \\
\hline Prior myocardial infarction, n (\%) & $71(2.9)$ & $48(3.9)$ & 0.11 \\
\hline Prior PCl, n (\%) & $275(11.1)$ & 138(11.1) & 1.00 \\
\hline ACEI/ARB, n (\%) & $563(22.7)$ & $282(22.8)$ & 0.99 \\
\hline$\beta$ blocker, n (\%) & 2163(87.3) & 1075(86.8) & 0.64 \\
\hline CCB, n (\%) & $666(26.9)$ & $337(27.2)$ & 0.85 \\
\hline Statin, n (\%) & 1663(67.1) & $819(66.1)$ & 0.53 \\
\hline \multicolumn{4}{|c|}{$\begin{array}{l}\text { Values are given as mean + SD, or frequency n (percent). eGFR, estimated glomerular filtration rate; EF, } \\
\text { ejection fraction; ACS, acute coronary syndrome; PCI, percutaneous coronary intervention; ACEI, } \\
\text { angiotensin-converting enzyme inhibitors; ARB, angiotensin receptor blocker; CCB, calcium channel } \\
\text { blocker; SVG, saphenous vein graft; LAD, left anterior descending branch; LCX, left circumflex branch; } \\
\text { OM, obtuse marginal branch; RCA, right coronary artery }\end{array}$} \\
\hline
\end{tabular}




\begin{tabular}{|c|c|c|c|}
\hline & $\begin{array}{l}\text { Derivation cohort } \\
\mathrm{N}=2477\end{array}$ & $\begin{array}{l}\text { Validation cohort } \\
N=1239\end{array}$ & $P$ value \\
\hline Aspirin, $\mathrm{n}(\%)$ & $2316(93.5)$ & $1141(92.7)$ & 0.12 \\
\hline P2Y12 inhibitor, $n$ (\%) & $1616(65.2)$ & $781(63)$ & 0.19 \\
\hline Diabetes therapy, n (\%) & 2328(94) & 1155(93.2) & 0.13 \\
\hline Complex coronary lesions, n (\%) & $1118(60.3)$ & $581(62.9)$ & 0.20 \\
\hline On-pump, n (\%) & 251(10.1) & $141(11.4)$ & 0.26 \\
\hline Valve surgery, n (\%) & $114(4.6)$ & $70(5.6)$ & 0.17 \\
\hline Reoperation, n (\%) & $39(1.6)$ & $14(1.1)$ & 0.31 \\
\hline Intra-aortic balloon pump, $\mathrm{n}(\%)$ & 17(0.7) & $4(0.3)$ & 0.25 \\
\hline Number of SVGs & $3.08 \pm 0.82$ & $3.09 \pm 0.85$ & 0.34 \\
\hline Number of vessels with lesion & $2.11 \pm 0.84$ & $2.10 \pm 0.86$ & 0.26 \\
\hline Left main, $\mathrm{n}(\%)$ & $542(21.9)$ & $279(22.5)$ & 0.70 \\
\hline LAD/Diagonal, n (\%) & $2033(82.1)$ & $992(80.1)$ & 0.21 \\
\hline LCX/OM, n (\%) & $1662(67.1)$ & $883(71.3)$ & 0.03 \\
\hline RCA, n (\%) & 1776(71.7) & $885(71.4)$ & 0.89 \\
\hline SVG occlusion, n (\% patients) & $643(26)$ & $316(25.5)$ & 0.78 \\
\hline
\end{tabular}

\subsection{Statistical analysis and predictive model development}

Categorical variables are presented as number (percentage) and continuous variables as mean \pm standard deviation. $\chi 2$ or Fisher's exact test was used for analysis of categorical variables. Unpaired student's t-test was used for analysis of normally distributed continuous variables. Time-to-event was calculated in months from the date of primary CABG to the date of postoperative invasive angiography or CTA. The construction of this predictive risk score was based on the method used in development of the Framingham risk score system (19). Development of the predictive risk score had three steps. First, to determine covariates that were independent risk factors for occlusion, we entered significant $(P<0.05)$ variables from the univariate analysis and/or those with clinical relevance into a multivariable Cox proportional hazards regression model using backward elimination with a critical $P<0.05$. Second, to define the continuous risk factor, categories based on SVG number and number of vessels with lesions 
were used to determine a reference value $\left(\mathrm{W}_{\mathrm{ij}}\right)$. Categorical risk factors were modelled using sets of indicator variables. The referent risk factor profile ( $\mathrm{W}_{\mathrm{iREF}}$ ) was considered "not at risk" of SVG occlusion, and defined as category 1 . We computed the distance from the category reference value to the referent value for each risk factor category by regression analysis using $\beta i\left(W_{i j}-W_{i R E F}\right)$. The $\beta$ coefficient of the SVG number (continuous variable) was used as a reference standard and assigned one point, with the constant $B$ equaling 0.12 . Finally, the points associated with each category of risk factor were calculated via Points $\mathrm{s}_{\mathrm{ij}}=\beta \mathrm{i}\left(\mathrm{W}_{\mathrm{ij}}-\mathrm{W}_{\mathrm{iREF}}\right) / \mathrm{B}$. The specific risk of each score was then calculated according to the previously described formula (19).

Model validation had two steps: discrimination and calibration. Discrimination of the predictive risk model was assessed using the c-index, which is equivalent to the area under the receiver operating characteristic (ROC) curve for binary dependent variables $(20,21)$, as an overall measure of model discrimination. Model calibration was assessed graphically using a calibration curve and observed versus model-predicted late occlusion in risk groups. All statistical analyses were done with $\mathrm{R}$ (www.rproject.org; version 3.2.4) and SPSS (SPSS Inc., Chicago, Illinois, USA.; version 25.0). Graphs were generated using GraphPad Prism 8.3.0. All sections have been prepared according to the TRIPOD statement (22).

\subsection{Missing data}

Data for some variables were missing from our data set. Multiple imputation by chained equations (MICE) was used to impute missing values (23), which is superior to other methods (e.g. regression method, delete and mean method) and demonstrates stable performance.

\section{Results}

\subsection{Study population}

During the follow up period, 959 (25.8\%) patients developed at least one SVG occlusion. At the graft-level, $1583(18.8 \%)$ of the 8422 grafts occluded within 5 years after primary CABG. This cohort was divided, after random sampling, into a derivation cohort $(n=2477,66.7 \%)$ and a validation cohort $(n=1239$, $33.3 \%)$. Baseline characteristics of patients in the derivation and validation cohorts were similar. The mean age of the derivation cohort was $59.73 \pm 8.66$ years and $76.7 \%$ were men. A total of $1118(60.3 \%)$ patients in the derivation cohort had complex coronary lesions, defined as left main lesion and/or triplevessel lesion, 2163 (87.3\%) received $\beta$-blocker therapy, and 2316 (93.5\%) took aspirin after surgery (Table 1).

\subsection{Prediction modeling for late SVG occlusion}

In the multivariate COX proportional hazard model, 11 variables were identified as independent predictors for SVG occlusion: sex, estimated glomerular filtration rate(eGFR) $<90$, smoking, dyslipidemia, hyperuricemia, prior percutaneous coronary intervention (PCI), on-pump surgery, SVG number, lesion 
vessel number (including only vessels of the left anterior descending branch, circumflex artery, and right coronary artery), use of angiotensin-converting enzyme inhibitors (ACEI)/angiotensin receptor blockers (ARB), and use of calcium channel blockers (CCB; Table 2). Table 3 shows the $\beta$ regression coefficient $(\beta i)$, reference value $\left(W_{i j}\right)$, referent risk factor profile $\left(W_{i R E F}\right)$, final point totals, and mean or proportion for each variable. Table 4 shows the cumulative risk score associated with risk of late occlusion, with the theoretical range of point values between -9 to 24 . Since there are few patients in the lower and upper ranges of the distribution, we shortened the risk table to avoid overstating the precision of the risk estimates. For example, a female patient (risk score $=4$ ) with eGFR $<90(2)$ and hyperuricemia (2), a history of percutaneous coronary intervention ( $\mathrm{PCl} ; 2)$, and was a triple-vessel lesion patient (8), would have a final risk score of 18 , with a predictive risk of $41 \%$ at 5 years of follow-up.

Table 2

Independent predictors for late SVG occlusion in the final model

\begin{tabular}{|llll|}
\hline Risk factors & Regression coefficient & Odds ratio(95\% Cl) & Mean or proportion \\
\hline SVG number & 0.12 & $1.13(1.03-1.24)$ & 2.26 \\
\hline Number of vessels with lesion & 0.451 & $1.57(1.41-1.75)$ & 2.11 \\
\hline Female & 0.515 & $1.67(1.37-2.04)$ & 0.233 \\
\hline Dyslipidemia & 0.519 & $1.68(1.43-1.97)$ & 0.577 \\
\hline eGFR $<90$ & 0.21 & $1.23(1.06-1.44)$ & 0.455 \\
\hline Hyperuricemia & 0.222 & $1.25(1.03-1.51)$ & 0.183 \\
\hline Smoking & 0.318 & $1.38(1.16-1.63)$ & 0.469 \\
\hline ACEI/ABB & -0.589 & $0.56(0.46-0.67)$ & 0.227 \\
\hline Prior PCI & 0.213 & $1.24(1.01-1.54)$ & 0.111 \\
\hline $\begin{array}{l}\text { CCB } \\
\text { On-pump }\end{array}$ & -0.228 & $0.80(0.67-0.95)$ & 0.269 \\
\hline $\begin{array}{l}\text { The final model was adjusted for age, obesity, hypertension, aspirin, P2Y12 inhibitor, complex } \\
\text { coronary lesions. Cl, Confidence interval; SVG, saphenous vein graft; ACEl, angiotensin-converting } \\
\text { enzyme inhibitors; ARB, angiotensin receptor blocker; CCB, calcium channel blocker; PCl, } \\
\text { percutaneous coronary intervention, eGFR, estimated glomerular filtration rate. }\end{array}$ & \\
\hline
\end{tabular}


Table 3

Predictors from Cox proportional hazard model used in the construction of the SVG occlusion score

\begin{tabular}{|c|c|c|c|c|c|}
\hline Risk factors & Categories & $\begin{array}{l}\text { Reference value } \\
\text { (Wij) }\end{array}$ & $\beta i$ & $\begin{array}{l}\beta i(W i j ~-~ \\
\text { Wiref) }\end{array}$ & point \\
\hline \multirow[t]{5}{*}{ SVG number } & 1 & 1 = W1ref & \multirow[t]{5}{*}{0.12} & 0 & 0 \\
\hline & 2 & 2 & & 0.12 & 1 \\
\hline & 3 & 3 & & 0.24 & 2 \\
\hline & 4 & 4 & & 0.36 & 3 \\
\hline & $>4$ & 5 & & 0.48 & 4 \\
\hline \multirow{4}{*}{$\begin{array}{l}\text { Number of vessels with } \\
\text { lesion }\end{array}$} & 0 & 0 & \multirow[t]{4}{*}{0.45} & -0.45 & -4 \\
\hline & 1 & $1=$ w2ref & & 0 & 0 \\
\hline & 2 & 2 & & 0.45 & 4 \\
\hline & 3 & 3 & & 1.11 & 8 \\
\hline \multirow[t]{2}{*}{ Female } & No & $0=$ W4ref & \multirow[t]{2}{*}{0.52} & 0 & 0 \\
\hline & Yes & 1 & & 0.52 & 4 \\
\hline \multirow[t]{2}{*}{ Dyslipidemia } & No & $0=$ W3ref & \multirow[t]{2}{*}{0.52} & 0 & 0 \\
\hline & Yes & 1 & & 0.52 & 4 \\
\hline \multirow[t]{2}{*}{ eGFR $<90$} & No & $0=$ W5ref & \multirow[t]{2}{*}{0.21} & 0 & 0 \\
\hline & Yes & 1 & & 0.21 & 2 \\
\hline \multirow[t]{2}{*}{ Hyperuricemia } & No & $0=$ W7ref & \multirow[t]{2}{*}{0.222} & 0 & 0 \\
\hline & Yes & 1 & & 0.222 & 2 \\
\hline \multirow[t]{2}{*}{ Smoking } & No & $0=$ W6ref & \multirow[t]{2}{*}{0.318} & 0 & 0 \\
\hline & Yes & 1 & & 0.318 & 3 \\
\hline \multirow[t]{2}{*}{ ACEI/ARB } & No & $0=$ W8ref & \multirow[t]{2}{*}{-0.589} & 0 & 0 \\
\hline & Yes & 1 & & -0.589 & -5 \\
\hline \multirow[t]{2}{*}{ Prior PCl } & No & $0=$ W9ref & \multirow[t]{2}{*}{0.213} & 0 & 0 \\
\hline & Yes & 1 & & 0.213 & 2 \\
\hline CCB & No & $0=$ W10ref & -0.228 & 0 & 0 \\
\hline
\end{tabular}

SVG, saphenous vein graft; $A C E I$, angiotensin-converting enzyme inhibitors; $A R B$, angiotensin receptor blocker; $\mathrm{CCB}$, calcium channel blocker; $\mathrm{PCl}$, percutaneous coronary intervention; eGFR, estimated glomerular filtration rate 


\begin{tabular}{|c|c|c|c|c|c|}
\hline Risk factors & Categories & $\begin{array}{l}\text { Reference value } \\
\text { (Wij) }\end{array}$ & $\beta \mathbf{i}$ & $\begin{array}{l}\beta i(W i j ~-~ \\
\text { Wiref) }\end{array}$ & point \\
\hline & Yes & 1 & & -0.228 & -2 \\
\hline \multirow[t]{2}{*}{ Off-pump } & No & 0 = W11 ref & \multirow[t]{2}{*}{-0.458} & 0 & 0 \\
\hline & Yes & 1 & & -0.520 & -4 \\
\hline
\end{tabular}


Table 4

Cumulative risk score and associated risk of late SVG occlusion

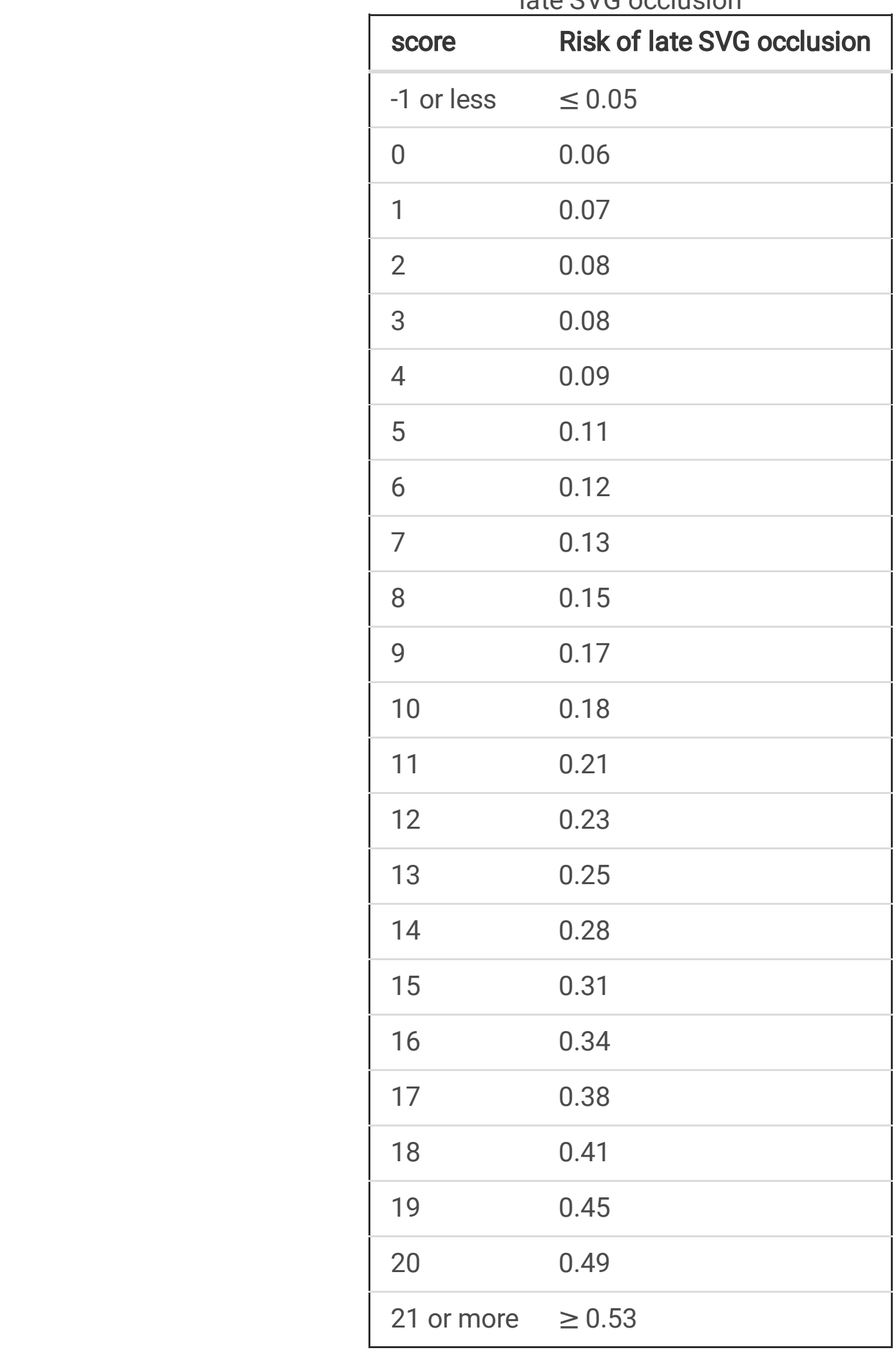

3.3 Summary measures of calibration and discrimination

Discrimination of the predictive risk model was assessed using the c-index. The final predictive model had good performance for prediction of late SVG occlusion in the derivation cohort (c-index $=0.0 .694$; 
$95 \% \mathrm{Cl}, 0.674-0.714)$. The predictive model also had good performance in the validation cohort (c-index $=0.734 ; 95 \% \mathrm{Cl}, 0.7659-0.801)$.

Patients were classified into four groups representing the quartiles of risk. The first to fourth quartiles contained 299, 342, 265, and 333 patients, respectively, and corresponded to a score of $\leq 5,6-10,11-13$, and $\geq 14$, respectively. Discrimination was good, as is shown in the plot of cumulative rate of late SVG occlusion for patients classified into each of the four risk groups (Fig. 2). The observed versus predicted rates of late SVG occlusion in the first to fourth quartiles is shown in Fig. 3. The exact occlusion rates for each risk group (observed vs. predicted) were $16.4 \%$ versus $7.8 \%, 23.1 \%$ versus $15.3 \%, 25.2 \%$ versus $23.9 \%$, and $36.3 \%$ versus $36.2 \%$, respectively. The difference between the observed and model-predicted late SVG occlusion risks was $8.6,7.8,1.3$, and $0.1 \%$ for risk groups $1-4$, respectively. There was an underprediction of SVG occlusion in the two lower risk groups, and a relatively precise prediction in the two higher risk groups. A modest underestimation in the lower probability range and a relatively precise estimation in the higher probability range of late SVG occlusion were also evident from calibration plots (Figs. 4 and 5). Figure 4 presents the observed late SVG occlusion rate versus model-predicted risk in groups based on the SVG occlusion risk score. In Fig. 5, the calibration plot presents the mean predicted risk of late SVG occlusion against the observed proportion of late SVG occlusion for 21 groups based on the calculated SVG occlusion risk score. Visually, it appeared to be a good calibration of both the predictive risk model and observed proportion across every risk score from 0-20.

\section{Discussion}

We developed a predictive risk score for saphenous vein graft SVG occlusion in patients with T2DM after CABG. We found that the model discrimination was good; in other words, the risk score was reliable in correctly classifying patients via risk stratification. However, the calibration was not ideal, which caused a modest underestimation of SVG occlusion for low risk patients, while demonstrating a relatively precise predictive performance for high risk patients. There are a total of 11 independent predictive factors in the scoring system that leads to calculation of a CABG patient's personalized risk of developing late SVG occlusion. The risk score developed in this study could guide treatment strategy by focusing on the likelihood of late SVG occlusion in patients with T2DM after CABG with high-risk factors, such as hyperuricemia and the use of ACEI/ARB or CCB, which are not currently addressed in treatment recommendations. This risk score has significant implications for patients with T2DM after CABG, as those with higher risk scores should be managed with greater vigilance and intensive treatment to effectively mitigate cardiovascular risk factors.

CABG is one of the most effective revascularization strategies for CAD, especially for patients with T2DM and multivessel diseases, and has been shown to reduce mortality and improve quality of life (24). However, SVG occlusion has an adverse impact on the prognosis of patients and increases the economic burden of health care systems (9). Among all grafts, diabetes was associated with an increased risk of graft occlusion(25). SVG occlusion can be classified into two types: early and late. Early SVG occlusion is primarily attributed to a technical failure that results in graft thrombosis and hyperplasia as the SVG is 
arterialized. Late SVG occlusion is primarily due to generalized neointimal hyperplasia and atherosclerosis, which occurs over the injured endothelium (2), which was associated with diabetes progression. The risk factors associated with late SVG occlusion have been evaluated in some studies $(10,12,14,18,26)$, but a widely accepted prediction model for late SVG occlusion in T2DM patients had not been previously developed. We have designed and validated a prediction model for late SVG occlusion in T2DM patients by using cohort data from a high-volume cardiac center. Previous studies have shown specific risk factors from patient-related, graft-related, and surgery-related perspectives. Female sex is an independent risk factor of SVG occlusion in early vein graft failure $(11,15,17)$, possibly due to smaller target vessel diameter of female patients. Cardiovascular risk factors like smoking, dyslipidemia, and a history of PCl have also been identified as risk factors of late SVG occlusion $(10,18)$. Uric acid level had never been considered relevant to SVG occlusion, however, clinical practice experience and prior research indicate that hyperuricemia may lead to kidney injury (27), and chronic kidney disease has been reported as a risk factor for vein graft disease $(12,13)$. Off-pump surgery for CABG without cardioplegia has been associated with lower graft patency rates compared with on-pump surgery. Additionally, the coagulopathy and platelet dysfunction induced by cardiopulmonary bypass can affect SVG patency $(26,28)$. From the graft-related and surgery-related perspectives, any use of SVGs is independently associated with reduced survival after coronary artery bypass surgery (29), which is consistent with the risk factors we have derived. Most patients with diseases with multiple lesions have diffuse lesions, suggesting that the condition of the graft may be poor; these patients have a higher rate of late SVG occlusion. As for medications, the use of ACEI/ARB and CCB are both protective factors for SVG occlusion, which may be related to the dilation of blood vessels, antispasmodics, and increased graft diameter. Furthermore, the effects of antihypertensive medications may contribute to reduced risk of SVG hyperplasia, which has been demonstrated in a study on early SVG occlusion (30).

A variety of cardiac surgery risk prediction models have been established, including the Society of Thoracic Surgeons (STS) score (31), the American College of Cardiology/American Heart Association (ACC / AHA) score (32), the European EuroSCORE(European System for Cardiac Operative Risk Evaluation score) (33), and its modified version, the EuroSCORE II (34). These prediction models were primarily used for evaluating perioperative risk. For SVG occlusion, the SAFINOUS-CABG score (16) is a model for early SVG occlusion, with risk factors that include sex, diabetes, dyslipidemia, active smoking, and SVG number, which are mostly consist with the risk factors identified in our study. A study by Joseph et al. also found that female sex and diabetes are risk factors for graft occlusion (17). Moreno et al, Wezel et al, and Yazdani et al found that atherosclerosis and plaque rupture are the main causes of late vein graft failure. The formation of atheromatous plaques is promoted by predisposing factors for atherosclerosis (e.g., high blood pressure, diabetes, smoking), and damage to the vein wall is induced by highly proliferative smooth muscle cells and expression and secretion of pro-inflammatory cytokines (35-38). These findings are consistent with some of our results. Domanski et al. focused on prognostic factors for atherosclerosis progression in saphenous vein grafts, hypothesized that dyslipidemia, prior myocardial infarction, female sex and current smoker status were associated with acceleration of the atherosclerosis progression in saphenous vein grafts, thereby leading to late SVG occlusion (39). 
Our study is the first large-scale comprehensive cohort-based development of a predictive model for late SVG occlusion in T2DM patients that could be used for risk stratification of CABG patients. The risk score system could inform clinical decision-making through calculation of individual risk for late SVG occlusion in T2DM patients. Assessment of the SVG risk score could improve surgical strategy and help in the development of personalized postoperative treatment plans. Proactive risk assessment and associated treatment may also be particularly cost-effective by reducing SVG occlusion and cardiovascular events in in T2DM patients after CABG.

We recognize that our study has limitations. First, this research is a retrospective investigation. Although we continuously enrolled patients with T2DM who underwent CABG, a small number of patients did not receive invasive angiography or CTA results during the follow-up time, which may result in selection bias. The time of postoperative invasive angiography or CTA depends on many factors. The most important factors are the patient's symptoms and the personal decision of the doctors providing outpatient services. Although this may affect the observation of the SVG occlusion, it is the best representation of the current context of clinical practice. There was also data missing from our database. Although we used MICE to impute missing values, bias is evitable. In addition, the absence of some variables, such as target vessel diameter, graft mean flow, and some surgical related items, leads to a risk of confounding. Also, microvascular disease, coronary atherosclerosis burden, progression and plaque composition, may need to be considered for a more refined risk stratification in these high-risk patients(40). Finally, our database was split into two groups randomly: one to develop a prediction model, and one to evaluate the predictive performance of the model. This design led to lack of power during model development $(22,41-43)$ and validation. Future validation studies carried out at different medical centers with different surgical strategies and external validation by other investigators would be welcome.

\section{Conclusions}

We developed a comprehensive prediction model for late SVG occlusion in T2DM patients based on a large cohort of CABG patients. The risk score had a good capacity for risk stratification, with a modest underestimation of SVG occlusion in T2DM patients for low risk patients and a relatively precise prediction among high risk patients. The scoring tool is an 11-variable risk scoring system that can independently predict late SVG occlusion in T2DM patients and be used to improve clinical management by identifying high-risk patients and informing surgical strategy.

\section{Abbreviations And Acronyms}

$\mathrm{ACC}=$ american college of cardiology

ACEl=angiotensin-converting enzyme inhibitors

$\mathrm{AHA}=$ american heart association

$A R B=$ angiotensin receptor blockers 
$\mathrm{CABG}=$ coronary artery bypass grafting

$C A D=$ coronary artery disease

$\mathrm{CCB}=$ calcium channel blockers

CTA=computed tomography angiography

eGFR=estimated glomerular filtration rate

EuroSCORE=european system for cardiac operative risk evaluation score

MICE=multiple imputation by chained equations

$\mathrm{PCl}=$ percutaneous coronary intervention

ROC=receiver operating characteristic

SAFINOUS-CABG=saphenous vein graft failure-an outcomes study in coronary artery bypass grafting

STS=society of thoracic surgeons

SVG=saphenous vein graft

T2DM=type 2 diabetes mellitus

\section{Declarations}

\section{Acknowledgement}

Not applicable

\section{Authors' contributions}

All authors contributed to: (1) acquisition of data, or substantial analysis and interpretation of data, and (2) final approval of the version to be published. Yujie Zhou and Xiaoli Liu contributed to drafting the article or revising it critically for important intellectual content. Yujie Zhou and Xiaoli Liu contributed equally to this work and should be considered co-corresponding authors. Yujing Cheng and Xiaoteng Ma made the primary contributions to conception and design, and should be considered co-first authors.

\section{Conflicts of Interest}

The authors declare that there are no conflicts of interest.

\section{Funding}

This work was supported by grants from the following: 
National Key Research and Development Program of China (2017YFC0908800)

Beijing Municipal Administration of Hospitals' Ascent Plan (DFL20150601) and Mission plan (SML20180601)

Beijing Municipal Health Commission "Project of Science and Technology Innovation Center" (PXM2019_026272_000006)0

\section{Availability of data and material}

Not applicable

\section{Ethics approval}

The protocol of this registry was approved by the ethics committee of Beijing Anzhen Hospital (no. 2017003X)

\section{Consent for publication}

All of the authors provided written informed consent for publication.

\section{References}

1. Strain WD, Paldanius PM. Diabetes, cardiovascular disease and the microcirculation. Cardiovasc Diabetol. 2018;17(1):57.

2. Motwani JG, Topol EJ. Aortocoronary saphenous vein graft disease: pathogenesis, predisposition, and prevention. Circulation. 1998;97(9):916-31.

3. Bundhun PK, Wu ZJ, Chen MH. Coronary artery bypass surgery compared with percutaneous coronary interventions in patients with insulin-treated type 2 diabetes mellitus: a systematic review and meta-analysis of 6 randomized controlled trials. Cardiovasc Diabetol. 2016;15:2.

4. Russo I, Penna C, Musso T, Popara J, Alloatti G, Cavalot F, et al. Platelets, diabetes and myocardial ischemia/reperfusion injury. Cardiovasc Diabetol. 2017;16(1):71.

5. Sabik JF, 3rd, Blackstone EH, Gillinov AM, Smedira NG, Lytle BW. Occurrence and risk factors for reintervention after coronary artery bypass grafting. Circulation. 2006;114(1 Suppl):I454-60.

6. Brilakis ES, Rao SV, Banerjee S, Goldman S, Shunk KA, Holmes DR, Jr., et al. Percutaneous coronary intervention in native arteries versus bypass grafts in prior coronary artery bypass grafting patients: a report from the National Cardiovascular Data Registry. JACC Cardiovascular interventions. 2011;4(8):844-50.

7. Parang P, Arora R. Coronary vein graft disease: pathogenesis and prevention. Can J Cardiol. 2009;25(2):e57-62.

8. Gaudino M, Antoniades C, Benedetto U, Deb S, Di Franco A, Di Giammarco G, et al. Mechanisms, Consequences, and Prevention of Coronary Graft Failure. Circulation. 2017;136(18):1749-64. 
9. Samano N, Bodin L, Karlsson J, Geijer H, Arbeus M, Souza D. Graft patency is associated with higher health-related quality of life after coronary artery bypass surgery. Interact Cardiovasc Thorac Surg. 2017;24(3):388-94.

10. Goldman S, Zadina K, Moritz T, Ovitt T, Sethi G, Copeland JG, et al. Long-term patency of saphenous vein and left internal mammary artery grafts after coronary artery bypass surgery: results from a Department of Veterans Affairs Cooperative Study. J Am Coll Cardiol. 2004;44(11):2149-56.

11. McLean RC, Nazarian SM, Gluckman TJ, Schulman SP, Thiemann DR, Shapiro EP, et al. Relative importance of patient, procedural and anatomic risk factors for early vein graft thrombosis after coronary artery bypass graft surgery. J Cardiovasc Surg (Torino). 2011;52(6):877-85.

12. Wellenius GA, Mukamal KJ, Winkelmayer WC, Mittleman MA. Renal dysfunction increases the risk of saphenous vein graft occlusion: results from the Post-CABG trial. Atherosclerosis. 2007;193(2):41420.

13. Zhang L, Wu JH, Otto JC, Gurley SB, Hauser ER, Shenoy SK, et al. Interleukin-9 mediates chronic kidney disease-dependent vein graft disease: a role for mast cells. Cardiovasc Res. 2017;113(13):1551-9.

14. Takagi H, Matsui M, Umemoto T. Lower graft patency after off-pump than on-pump coronary artery bypass grafting: an updated meta-analysis of randomized trials. J Thorac Cardiovasc Surg. 2010;140(3):e45-7.

15. Tan ES, van der Meer J, Jan de Kam P, Dunselman PH, Mulder BJ, Ascoop CA, et al. Worse clinical outcome but similar graft patency in women versus men one year after coronary artery bypass graft surgery owing to an excess of exposed risk factors in women. CABADAS. Research Group of the Interuniversity Cardiology Institute of The Netherlands. Coronary Artery Bypass graft occlusion by Aspirin, Dipyridamole and Acenocoumarol/phenoprocoumon Study. J Am Coll Cardiol. 1999;34(6):1760-8.

16. Antonopoulos AS, Odutayo A, Oikonomou EK, Trivella M, Petrou M, Collins GS, et al. Development of a risk score for early saphenous vein graft failure: An individual patient data meta-analysis. J Thorac Cardiovasc Surg. 2019.

17. Sabik JF, 3rd, Lytle BW, Blackstone EH, Houghtaling PL, Cosgrove DM. Comparison of saphenous vein and internal thoracic artery graft patency by coronary system. Ann Thorac Surg. 2005;79(2):54451 ; discussion -51 .

18. Voors AA, van Brussel BL, Plokker HW, Ernst SM, Ernst NM, Koomen EM, et al. Smoking and cardiac events after venous coronary bypass surgery. A 15-year follow-up study. Circulation. 1996;93(1):42-7.

19. Sullivan LM, Massaro JM, D'Agostino RB, Sr. Presentation of multivariate data for clinical use: The Framingham Study risk score functions. Stat Med. 2004;23(10):1631-60.

20. Sartipy U, Dahlstrom U, Edner M, Lund LH. Predicting survival in heart failure: validation of the MAGGIC heart failure risk score in 51,043 patients from the Swedish heart failure registry. Eur J Heart Fail. 2014;16(2):173-9. 
21. Alba AC, Agoritsas T, Walsh M, Hanna S, lorio A, Devereaux PJ, et al. Discrimination and Calibration of Clinical Prediction Models: Users' Guides to the Medical Literature. JAMA. 2017;318(14):1377-84.

22. Collins GS, Reitsma JB, Altman DG, Moons KG. Transparent Reporting of a multivariable prediction model for Individual Prognosis or Diagnosis (TRIPOD): the TRIPOD statement. Ann Intern Med. 2015;162(1):55-63.

23. White IR, Royston P, Wood AM. Multiple imputation using chained equations: Issues and guidance for practice. Stat Med. 2011;30(4):377-99.

24. Serruys PW, Morice MC, Kappetein AP, Colombo A, Holmes DR, Mack MJ, et al. Percutaneous coronary intervention versus coronary-artery bypass grafting for severe coronary artery disease. $\mathrm{N}$ Engl J Med. 2009;360(10):961-72.

25. Desai ND, Naylor CD, Kiss A, Cohen EA, Feder-Elituv R, Miwa S, et al. Impact of patient and targetvessel characteristics on arterial and venous bypass graft patency: insight from a randomized trial. Circulation. 2007;115(6):684-91.

26. Shroyer AL, Hattler B, Wagner TH, Collins JF, Baltz JH, Quin JA, et al. Five-Year Outcomes after OnPump and Off-Pump Coronary-Artery Bypass. N Engl J Med. 2017;377(7):623-32.

27. Albu A, Para I, Porojan M. Uric Acid and Arterial Stiffness. Ther Clin Risk Manag. 2020;16:39-54.

28. Zhang B, Zhou J, Li H, Liu Z, Chen A, Zhao Q. Comparison of graft patency between off-pump and on-pump coronary artery bypass grafting: an updated meta-analysis. Ann Thorac Surg. 2014;97(4):1335-41.

29. Royse A, Pawanis Z, Canty D, Ou-Young J, Eccleston D, Ajani A, et al. The effect on survival from the use of a saphenous vein graft during coronary bypass surgery: a large cohort study. Eur $\mathrm{J}$ Cardiothorac Surg. 2018;54(6):1093-100.

30. Une D, Kulik A, Voisine P, Le May M, Ruel M. Correlates of saphenous vein graft hyperplasia and occlusion 1 year after coronary artery bypass grafting: analysis from the CASCADE randomized trial. Circulation. 2013;128(11 Suppl 1):S213-8.

31. Edwards FH, Grover FL, Shroyer AL, Schwartz M, Bero J. The Society of Thoracic Surgeons National Cardiac Surgery Database: current risk assessment. Ann Thorac Surg. 1997;63(3):903-8.

32. Eagle KA, Guyton RA, Davidoff R, Ewy GA, Fonger J, Gardner TJ, et al. ACC/AHA guidelines for coronary artery bypass graft surgery: executive summary and recommendations : A report of the American College of Cardiology/American Heart Association Task Force on Practice Guidelines (Committee to revise the 1991 guidelines for coronary artery bypass graft surgery). Circulation. 1999;100(13):1464-80.

33. Nashef SA, Roques F, Michel P, Gauducheau E, Lemeshow S, Salamon R. European system for cardiac operative risk evaluation (EuroSCORE). Eur J Cardiothorac Surg. 1999;16(1):9-13.

34. Nashef SA, Roques F, Sharples LD, Nilsson J, Smith C, Goldstone AR, et al. EuroSCORE II. Eur J Cardiothorac Surg. 2012;41(4):734-44; discussion 44-5.

35. Moreno K, Murray-Wijelath J, Yagi M, Kohler T, Hatsukami T, Clowes A, et al. Circulating inflammatory cells are associated with vein graft stenosis. J Vasc Surg. 2011;54(4):1124-30. 
36. Wezel A, de Vries MR, Lagraauw HM, Foks AC, Kuiper J, Quax PH, et al. Complement factor C5a induces atherosclerotic plaque disruptions. J Cell Mol Med. 2014;18(10):2020-30.

37. Yazdani SK, Farb A, Nakano M, Vorpahl M, Ladich E, Finn AV, et al. Pathology of drug-eluting versus bare-metal stents in saphenous vein bypass graft lesions. JACC Cardiovascular interventions. 2012;5(6):666-74

38. Caliskan E, de Souza DR, Boning A, Liakopoulos OJ, Choi YH, Pepper J, et al. Saphenous vein grafts in contemporary coronary artery bypass graft surgery. Nat Rev Cardiol. 2020;17(3):155-69.

39. Domanski MJ, Borkowf CB, Campeau L, Knatterud GL, White C, Hoogwerf B, et al. Prognostic factors for atherosclerosis progression in saphenous vein grafts: the postcoronary artery bypass graft (PostCABG) trial. Post-CABG Trial Investigators. J Am Coll Cardiol. 2000;36(6):1877-83.

40. Kennedy MW, Fabris E, Suryapranata. Is ischemia the only factor predicting cardiovascular outcomes in all diabetes mellitus patients? Cardiovascular Diabetology. 2017;16(1).

41. Altman DG, Vergouwe $Y$, Royston P, Moons KG. Prognosis and prognostic research: validating a prognostic model. BMJ. 2009;338:b605.

42. Moons KG, Kengne AP, Woodward M, Royston P, Vergouwe Y, Altman DG, et al. Risk prediction models: I. Development, internal validation, and assessing the incremental value of a new (bio)marker. Heart. 2012;98(9):683-90.

43. Steyerberg EW, Harrell FE, Jr., Borsboom GJ, Eijkemans MJ, Vergouwe Y, Habbema JD. Internal validation of predictive models: efficiency of some procedures for logistic regression analysis. J Clin Epidemiol. 2001;54(8):774-81.

\section{Figures}


4021 underwent primary CABG with type 2 diabetes mellitus

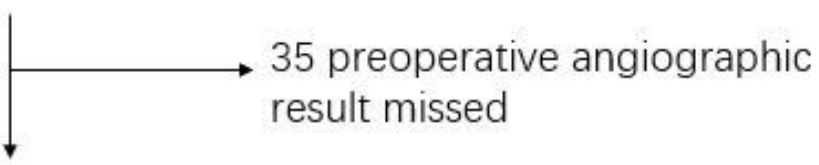

3986 with preoperative angiographic result

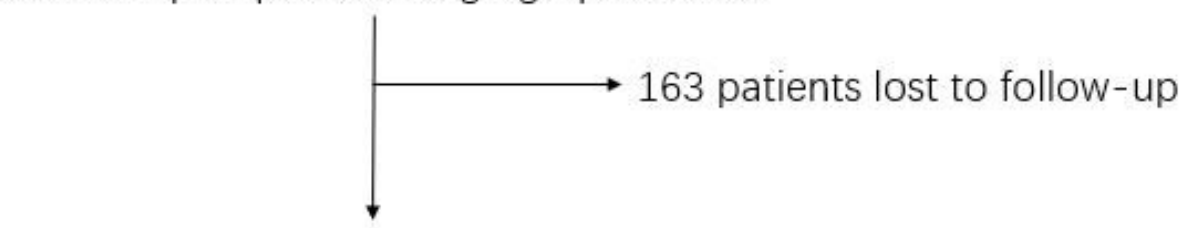

3823 individuals with five year follow-up

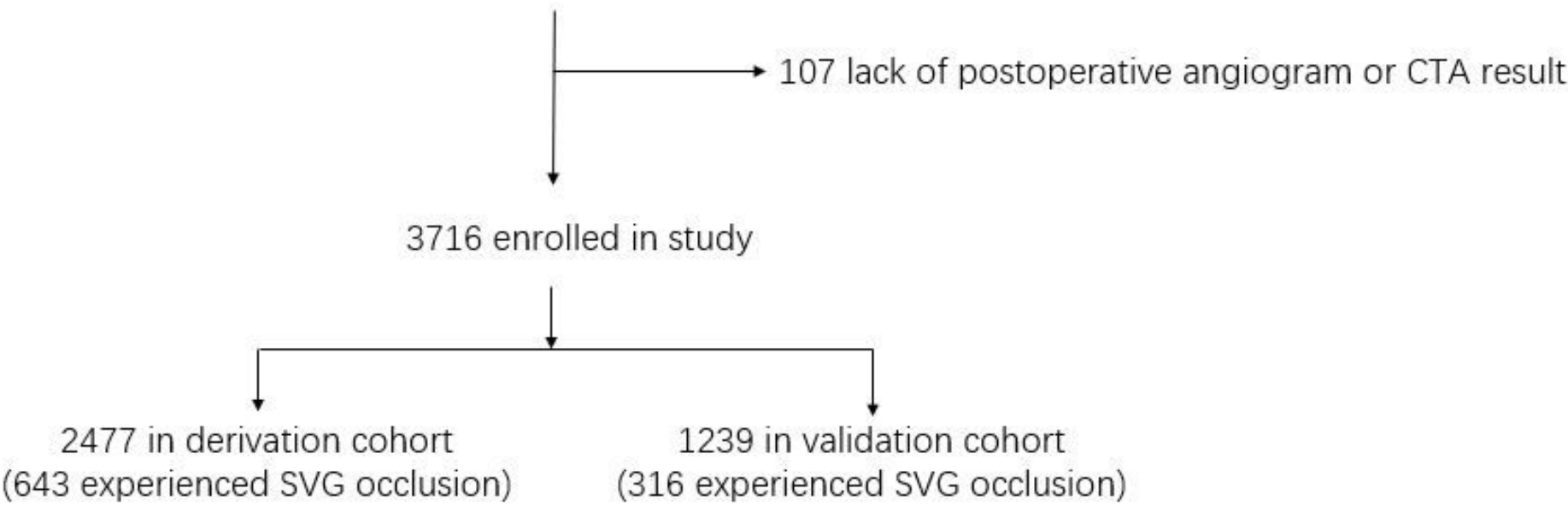

\section{Figure 1}

Flow of Study Participants in this Study. CABG: Coronary artery bypass grafting; CTA: coronary computed tomography angiography; SVG: saphenous vein graft. 


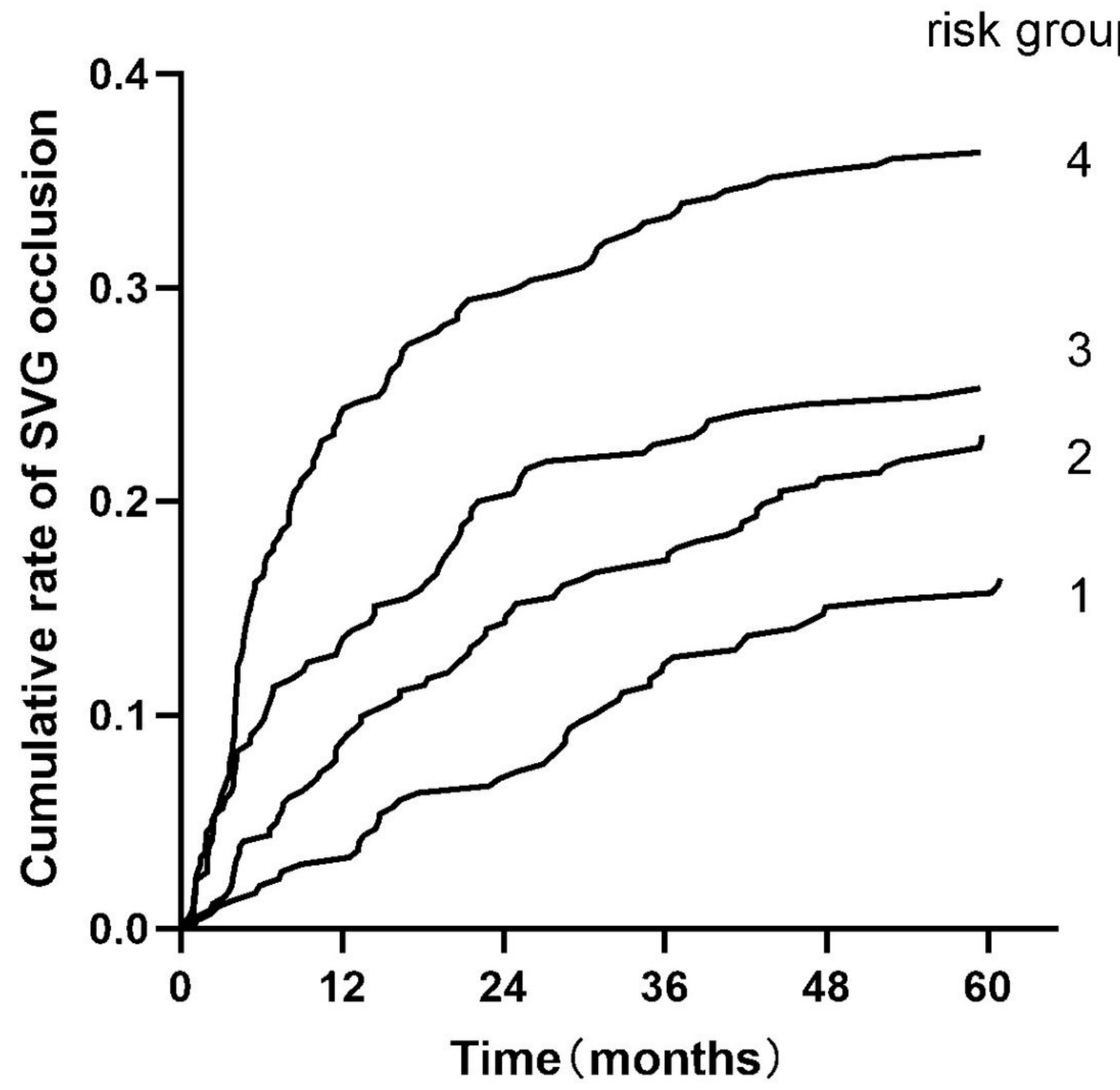

Figure 2

Cumulative rate of SVG occlusion in type 2 diabetes mellitus patients classified into four groups based on the developed risk score. Risk groups 1-4 represent risk scores $\leq 5,6-10,11-13$, and $\geq 14$. SVG: saphenous vein graft. 


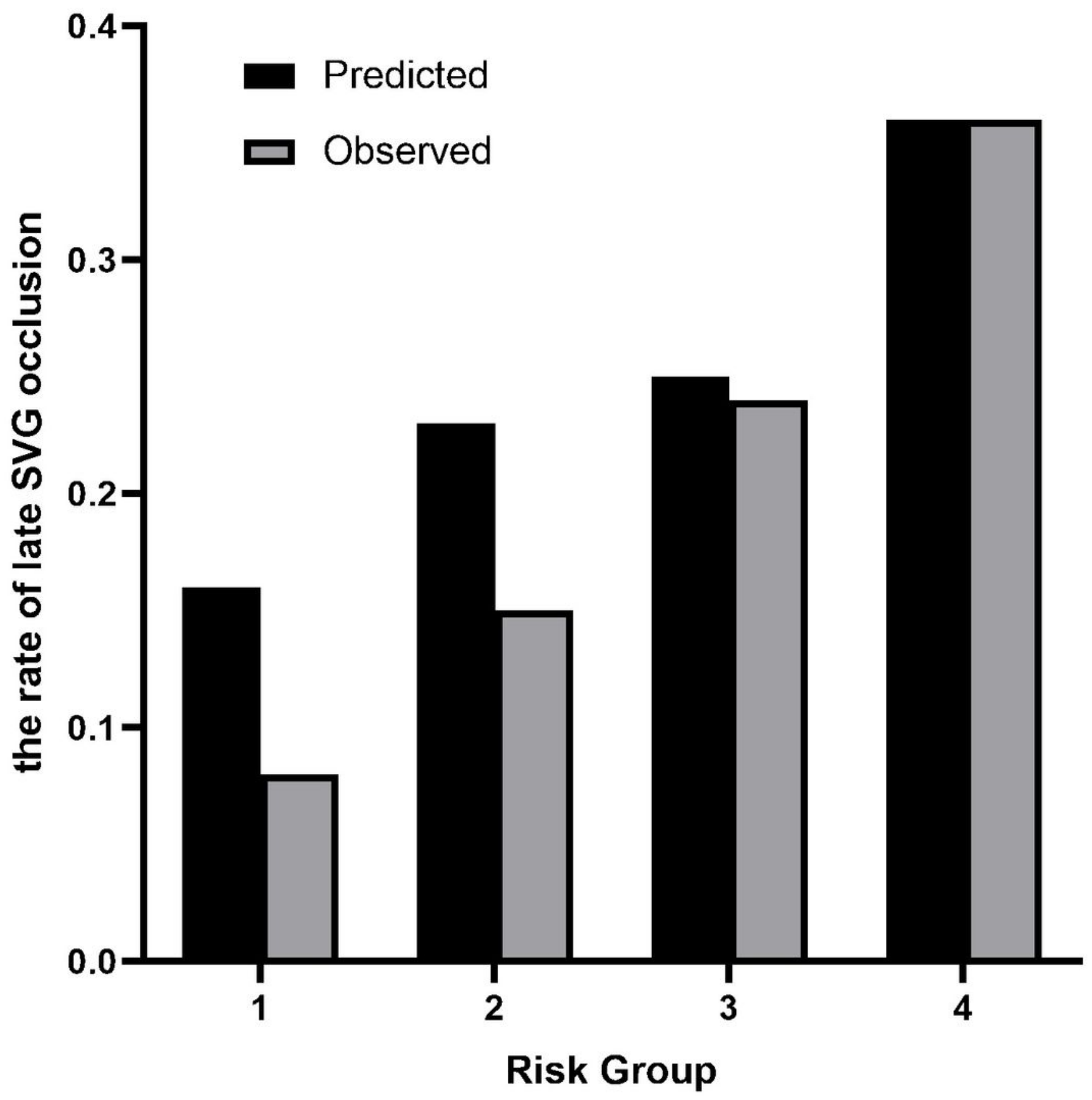

Figure 3

Observed vs. model-predicted late SVG occlusion for type 2 diabetes mellitus patients in four risk groups. Risk groups 1-4 represent risk scores $\leq 5,6-10,11-13$, and $\geq 14$. SVG: saphenous vein graft. 


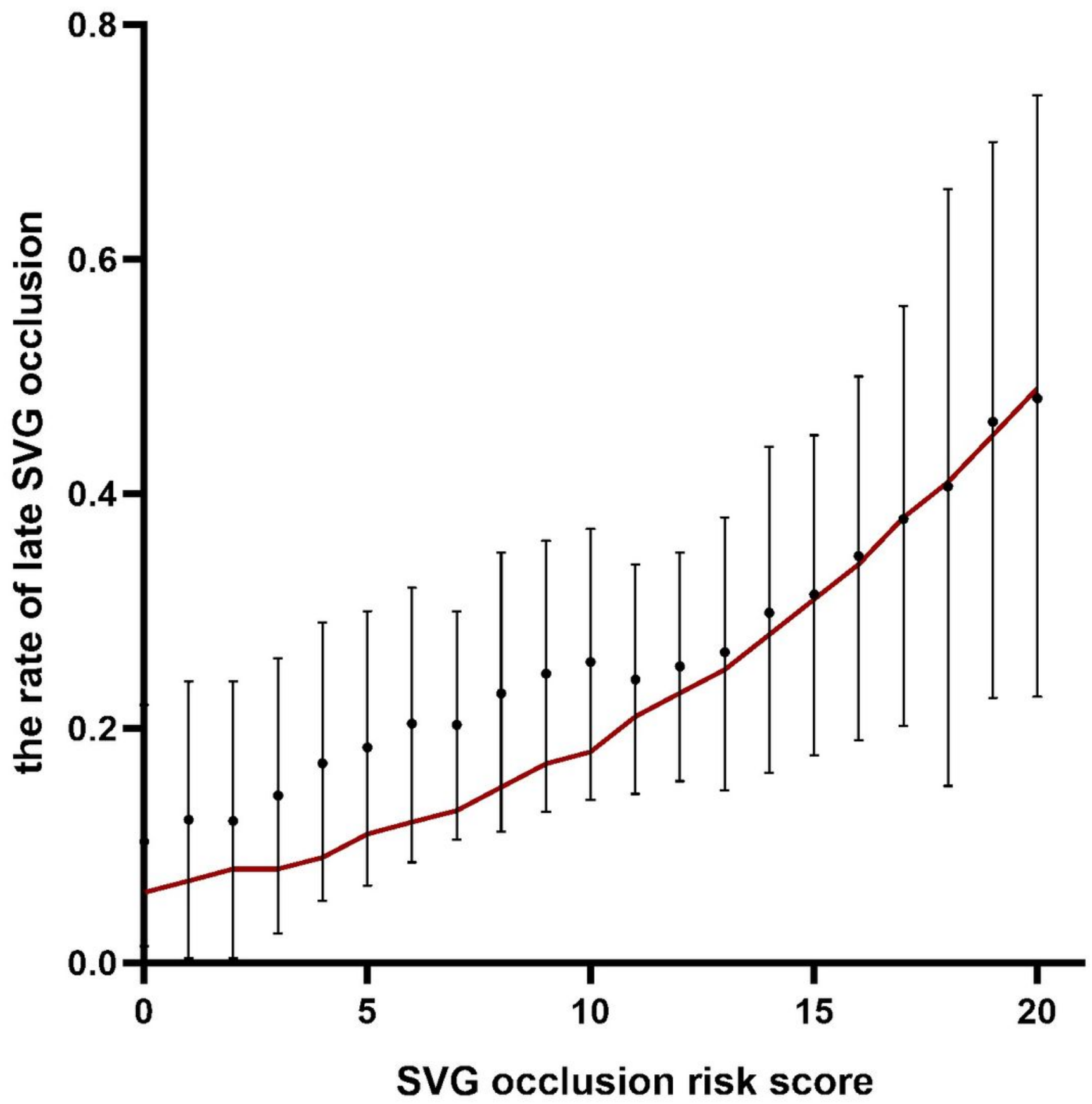

Figure 4

Observed rate of occlusion with $95 \%$ confidence interval vs. model-predicted risk of occlusion in groups based on the developed risk score. SVG: saphenous vein graft. 


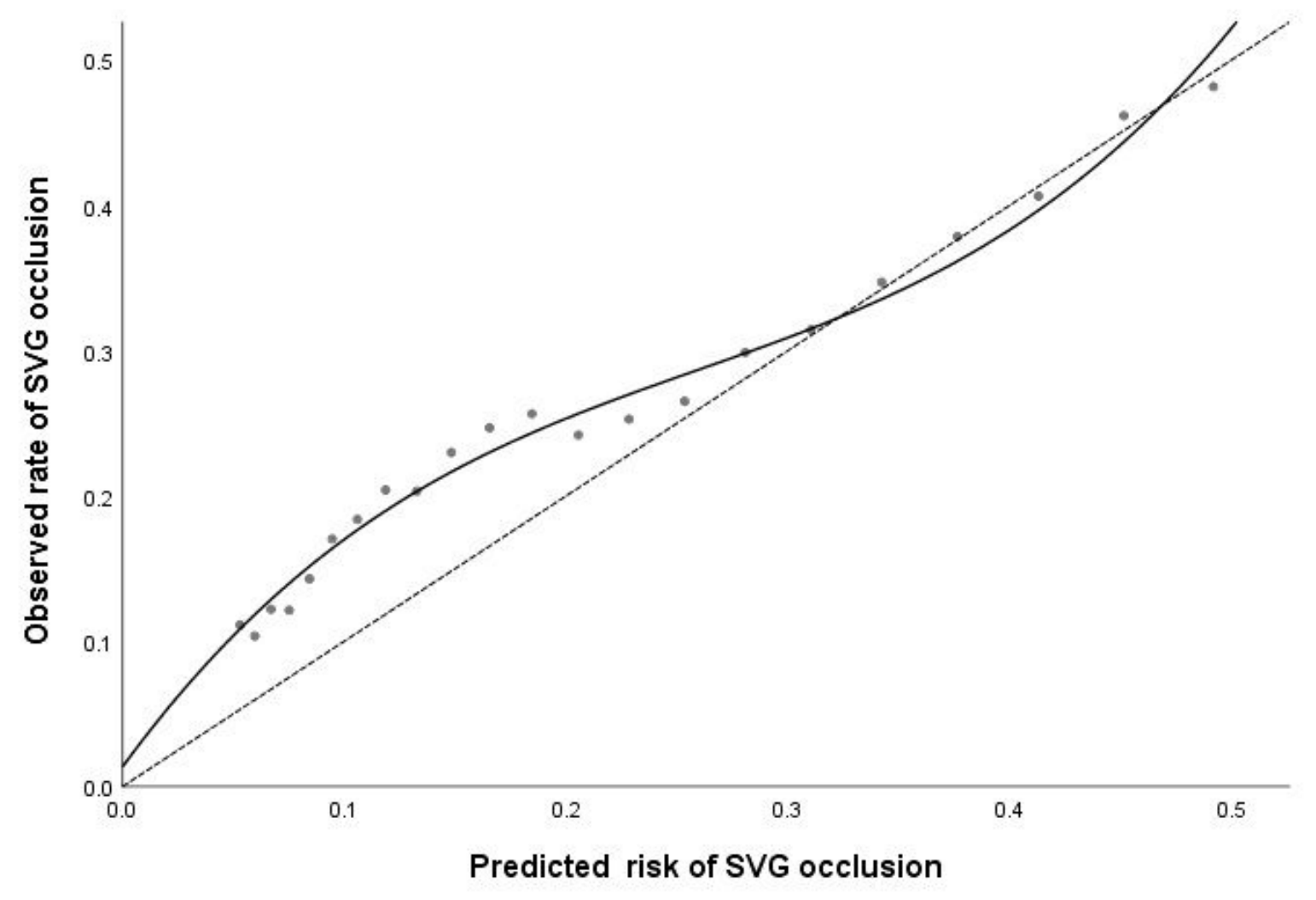

Figure 5

The calibration plot presents the predicted risk against the observed proportion of late SVG occlusion in T2DM patients for 21 groups based on the calculated SVG occlusion risk score. A locally weighted regression line is plotted to show the general trend. The dashed line is the line of reference shows the ideal calibration line. SVG: saphenous vein graft; T2DM: type 2 diabetes mellitus

\section{Supplementary Files}

This is a list of supplementary files associated with this preprint. Click to download.

- Figurelegend.docx

- renamed6d0c5.docx 